\title{
Venice flooding and sea level: past evolution, present issues, and future projections (introduction to the special issue)
}

\author{
Piero Lionello ${ }^{1}$, Robert J. Nicholls ${ }^{2}$, Georg Umgiesser ${ }^{3,4}$, and Davide Zanchettin ${ }^{5}$ \\ ${ }^{1}$ Department of Biological and Environmental Sciences and Technologies, Università del Salento, \\ Centro Ecotekne Pal. M - S.P. 6, Lecce Monteroni, Italy \\ ${ }^{2}$ Tyndall Centre for Climate Change Research, University of East Anglia, Norwich NR4 7TJ, United Kingdom \\ ${ }^{3}$ ISMAR (Marine Sciences Institute) - CNR (National Research Council of Italy), Castello 2737/F, 30122 Venice, Italy \\ ${ }^{4}$ Marine Research Institute, Klaipėda University, H. Manto 84, 92294 Klaipeda, Lithuania \\ ${ }^{5}$ Department of Environmental Sciences, Informatics, and Statistics, University Ca' Foscari of Venice, \\ Via Torino 155, 30172 Mestre, Venice, Italy
}

Correspondence: Piero Lionello (piero.lionello@unisalento.it)

Received: 29 October 2020 - Discussion started: 2 December 2020

Accepted: 18 May 2021 - Published: 1 September 2021

\begin{abstract}
Venice is an iconic place and a paradigm of huge historical and cultural values at risk. The frequency of the flooding of the city centre has dramatically increased in recent decades, and this threat is expected to continue to grow and even accelerate - through this century. This special issue is a collection of three review articles addressing different and complementary aspects of the hazards causing the floods of Venice, namely (1) the relative sea level rise, (2) the occurrence of extreme water heights, and (3) the prediction of extreme water heights and floods. It emerges that the effect of compound events poses critical challenges to the forecast of floods, particularly from the perspective of effectively operating the new mobile barriers (Modulo Sperimentale Elettromeccanico - MoSE) in Venice and that the relative sea level rise is the key factor determining the future growth of the flood hazard, so that the present defence strategy is likely to become inadequate within this century under a highemission scenario. Two strands of research are needed in the future. First, there is a need to better understand and reduce the uncertainty of the future evolution of the relative sea level and its extremes at Venice. However, this uncertainty might not be substantially reduced in the near future, reflecting the uncertain anthropogenic emissions and structural model features. Hence, complementary adaptive planning strategies appropriate for conditions of uncertainty should be explored and developed in the future.
\end{abstract}

\section{Motivation}

The great historic, ecologic, and economic interest of the city of Venice and its lagoon and the threats to which they are exposed are known around the world. In 1987, Venice and its lagoon were recognised as a UNESCO World Heritage Site based on the six criteria of outstanding cultural, environmental, and landscape universal value encompassing the historical and artistic relevance of the city and the exemplarity of the ecosystem (https://whc.unesco.org/en/list/394/, last access: 1 August 2021). In UNESCO's words, Venice symbolises "the people's victorious struggle against the elements as they managed to master a hostile nature" and its semilacustrine habitat "has become vulnerable as a result of irreversible natural and climate changes".

The history and the very essence of Venice are tightly intertwined with the sea and the lagoon, which have represented a source of resources and wealth and a natural defence system against enemies. However, the threat of floods has always been present (Enzi and Camuffo, 1995). This hazard has been exacerbated by the increased rate of relative sea level (RSL) rise after the 1930s (Zanchettin et al., 2021a; Lionello et al., 2021; hereafter, Z2021 and L2021, respectively), posing serious and growing threats to the city of Venice and its lagoon. In fact, the recurrent floods that afflict Venice, referred to as "aqua alta" in the local dialect, are the best known and most debated symptom of the frailty 
of the Venetian lagoon system. The Venetian RSL has risen at an average rate of $2.5 \mathrm{~mm}$ per year in the past 150 years due to mean sea level rise and the sinking of the ground by natural and anthropogenic subsidence, which accelerated the RSL rise rate up to $5 \mathrm{~mm}$ per year in the period 1950 1970 (Z2021), leading to an increased frequency of floods (L2021). The lowest part of the central St Mark's Square is approximately $55 \mathrm{~cm}$ above the present mean sea level; nowadays, a positive water height anomaly (see Sect. 3) that is only a few centimetres above astronomical high tide (whose amplitude is about $50 \mathrm{~cm}$ ) can flood it.

The dramatic surge of 4 November 1966 showed, unequivocally, the need for counteracting an increasing hazard level. The event reached the highest ever recorded water height $(194 \mathrm{~cm}$ ) and persisted over $110 \mathrm{~cm}$ for $22 \mathrm{~h}$ (see L2021; De Zolt et al., 2006; Cavaleri et al., 2010). Figure 1 shows the flooding of the central monumental area at a time close to the peak of the 6 November 1966 event. In 1973, the Italian government established a legal framework, the Special Law for Venice, establishing objectives, responsibilities, regulations, actions, and funding to safeguard Venice and its lagoon. The solution finally approved by the Italian government is a system of large mobile barriers (Modulo Sperimentale Elettromeccanico - MoSE) at the three lagoon inlets. Barriers will be raised only during severe events, closing the lagoon inlets and preventing the water height from exceeding the safeguard level within the lagoon, while, under normal conditions, they lie at the bottom of the lagoon inlets, allowing water exchange and ship traffic between the lagoon and the Adriatic Sea. After a long planning phase, construction started in 2003, and it is foreseen that the barriers will be fully operational at the end of 2021. The recent event on 12 November 2019 (Cavaleri et al., 2020; Ferrarin et al., 2021), which has been the second highest water height $(189 \mathrm{~cm})$ ever measured in Venice by a tide gauge, has dramatically reconfirmed the need for an adequate defence system. November 2019 was the worst month since the beginning of the local tide gauge records for excessive high waters, with 15 events exceeding $110 \mathrm{~cm}$ and four events above $140 \mathrm{~cm}$. MoSE has already been operated for a few exceptional events, such as on 3 October 2020, when, for the first time, the lagoon was cut off, under real hazard conditions, from the Adriatic Sea. While the peak water height during the event was $130 \mathrm{~cm}$ in the Adriatic, it was kept at $70 \mathrm{~cm}$ in the lagoon and at St Mark's Square and flooding was avoided. Figure 2 shows an aerial view of the barriers blocking the lagoon inlets and the time series of the water height outside (Piattaforma CNR) and inside the lagoon (Punta della Salute - Canal Grande represents the tide gauge commonly used as reference for the sea level in the city centre).

A large volume of scientific literature considers the factors leading to the flooding of Venice, predicting the timing and intensity of the events, and describing changes in their frequency and intensity under future global warming scenarios. This special issue aims to critically review the current un-

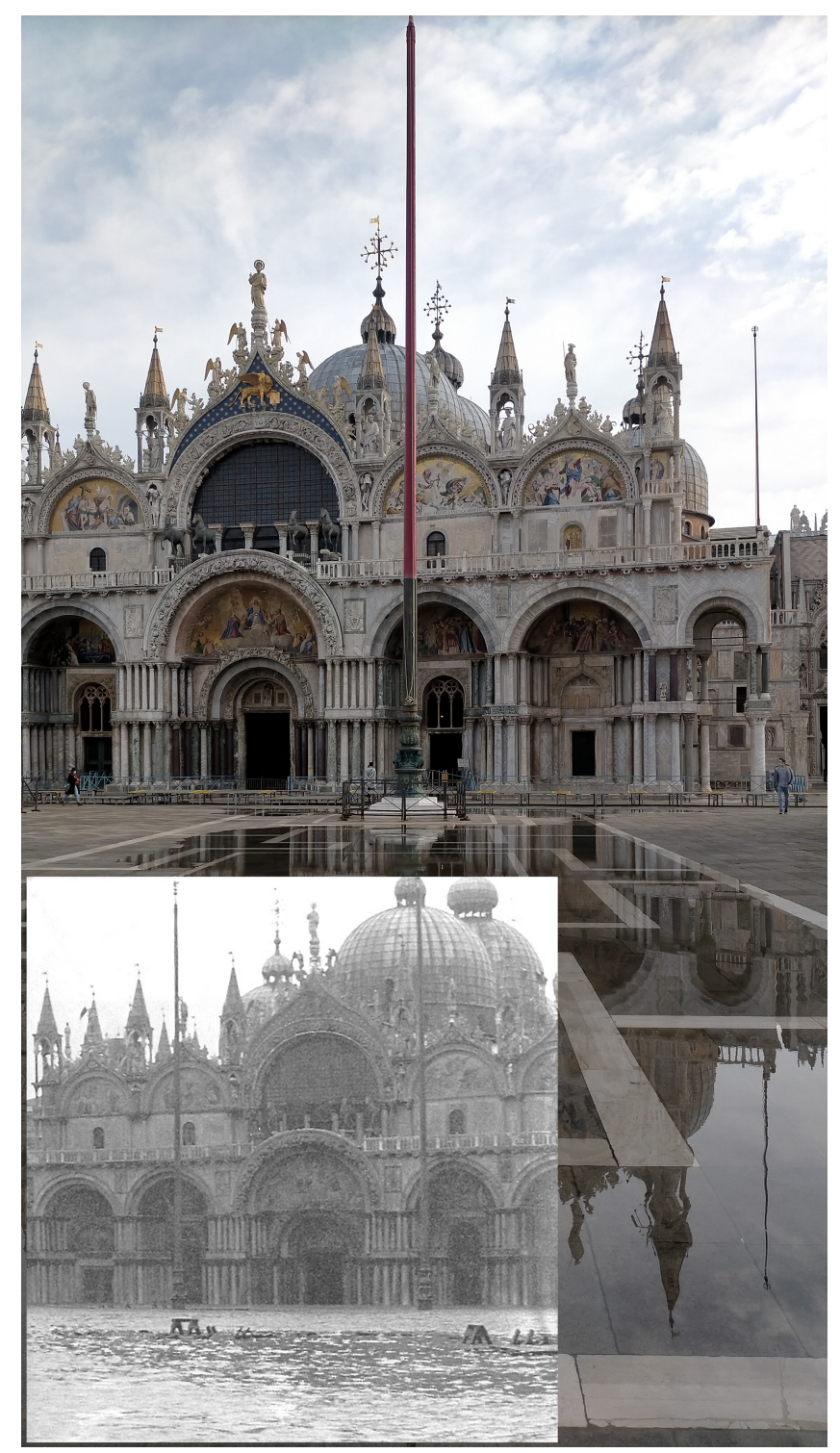

Figure 1. The present condition of St Mark's Square during the partial flooding of its lowest areas (estimated water height $-80 \mathrm{~cm}$ ) and a historical picture close to the time of highest level of the 4 November 1966 flood. The historical photograph is courtesy of Gianfranco Tagliapietra.

derstanding of the Venice flooding phenomenon. It considers the meteorological and climatic factors producing aqua alta, its prediction, and its historical and expected future variations under a globally changing climate. The synthesis is oriented toward clarifying consolidated knowledge, highlighting gaps in knowledge, and identifying major opportunities for progress.

This special issue comprises three review articles addressing three different and complementary aspects of the hazards causing the flooding of Venice. Z2021 consider the Venetian RSL evolution on multiple timescales and the factors deter- 
mining it. Umgiesser et al. (2021; hereafter U2021) describe the tools that have been developed and are currently being used for the prediction of the floods and give recommendations for further improvements. L2021 describe the factors leading to extreme water height events, their past evolution, and expected future trends under a climate change perspective. The outcomes of these papers provide a thorough critical review of the scientific literature. It is, hence, a basis for the assessment of present and future risks and helps to define the requirements of the adaptation strategies that are appropriate for Venice over the 21 st century.

This editorial provides an introduction to these three reviews. It briefly provides general background information by describing the geographical and historical setting (Sect. 2) and the phenomenology of surges and high water levels (Sect. 3). Section 4 describes the overall key findings produced by the three reviews. Implications for future flooding and its management are addressed in Sect. 5 as the concluding remarks.

\section{Geographical and historical setting}

The Venetian Lagoon covers about $550 \mathrm{~km}^{2}$ along about $50 \mathrm{~km}$ of low-lying coast within the easternmost boundary of the Po Plain and is connected to the northern Adriatic Sea through three tidal inlets, namely Lido, Malamocco, and Chioggia (Fig. 3). The historical city is located in the centre of the lagoon and is built at a low elevation on a base made of wooden piles reaching an underground hard layer and supporting the buildings.

The Venetian Lagoon is governed by a fragile equilibrium, which has been artificially preserved over the centuries by contrasting the natural evolution of this transitional area that is driven by coastal dynamics via geomorphological (e.g. erosion and sedimentation), chemical (e.g. salinification), biological, and ecological (e.g. loss of wetlands and other ecotopes) changes. Since the 15th century, Venetians have engaged in an enduring struggle against sedimentation in the lagoon, mainly by diverting away the major Adige, Bacchiglione, Brenta, Sile, and Piave rivers and their sediment supply, hence altering the morphology of the alluvial plain and the coastal margins. Bondesan and Furlanetto (2012) provide a recent assessment, based on historical cartography analysis, of the artificial fluvial diversions performed during the 16th and 17th centuries. More recent works in the 19th and 20th centuries include deepening of existing channels within the lagoon, the excavation of the "Canale dei Petroli" (Oil Channel) and the construction of breakwaters at the lagoon's mouths to allow modern ships to reach the ports of Giudecca and Marittima in the historic city and, more recently, Porto Marghera.

The tidal regime is a mixed semidiurnal cycle with a tidal range of more than $1 \mathrm{~m}$ at spring tide and only three components above $10 \mathrm{~cm}$, with the semidiurnal M2 and S2, and the diurnal $\mathrm{K} 1$ providing the largest contributions $(23,14$, and $16 \mathrm{~cm}$, respectively) both outside the lagoon inlets and in the city centre (Polli, 1952; Ferrarin et al., 2015)

Hydrodynamics linked to tidal exchange are critical for the great ecological variety and biodiversity of the Venetian Lagoon, with habitats ranging from tidal flats, marshlands, channels and canals, inlets, and tidal deltas with strong hydrodynamics and tidal renewals.

Changes in RSL may critically compromise the ecosystem functionality by inducing morphodynamic changes that alter the ecological vocation of such areas (Zanchettin et al., 2007). Former studies show that the increase in extreme floods since the mid-20th century is explained by the RSL rise (Lionello et al., 2012; L2021). Furthermore, future sea level rise (Z2021) might dramatically increase both the frequency of high sea level events and resulting floods, as well as increasing the duration and extent of flooding (L2021). This reinforces the need to understand the historical context of sea level change in Venice and consider its prognosis.

\section{Characteristics of surges and high water levels}

The floods of Venice are associated with the positive anomalies of the water height, defined as being the difference between the instantaneous sea level and the bottom level. The term "water height" is introduced because considering only sea level does not account for the fundamental role that the local vertical land motion (subsidence) has and will continue to have in the increased frequency of floods. The contributions leading to large water height anomalies are meteorological surges, seiches, tides, seasonal-to-decadal sea level variability, and long-term RSL changes. The meteorological surges result from three different contributions characterised by different timescales, i.e. surges produced by planetary atmospheric waves (PAWs; PAW surges), with durations from 10 to $100 \mathrm{~d}$, storm surges produced by midlatitude cyclones with timescales of a few days, meteotsunamis, and surges produced by mesoscale systems (with a short duration of a few hours). The characteristics of the different contributions and the criteria for their distinction are explained in Sect. 2.1 and 2.2 of L2021. Note that this terminology differs from Gregory et al. (2019) in that the term water height is introduced, and the surge is distinguished by three components, thus reserving the term "storm surge" for the component produced by the passage of a cyclone.

Meteorological surges in Venice are caused by a combination of various physical processes mainly triggered by the water level in the neighbouring Adriatic Sea. The main component of extreme events is the storm surge produced mostly by the southeasterly wind (sirocco), pushing the water against the northwestern end of the Adriatic Sea (wind set-up), and the low atmospheric pressure that increases the mean sea level by $1 \mathrm{~cm} / \mathrm{mbar}$ of pressure decrease (inverse barometer effect). The surge produced by atmospheric plane- 

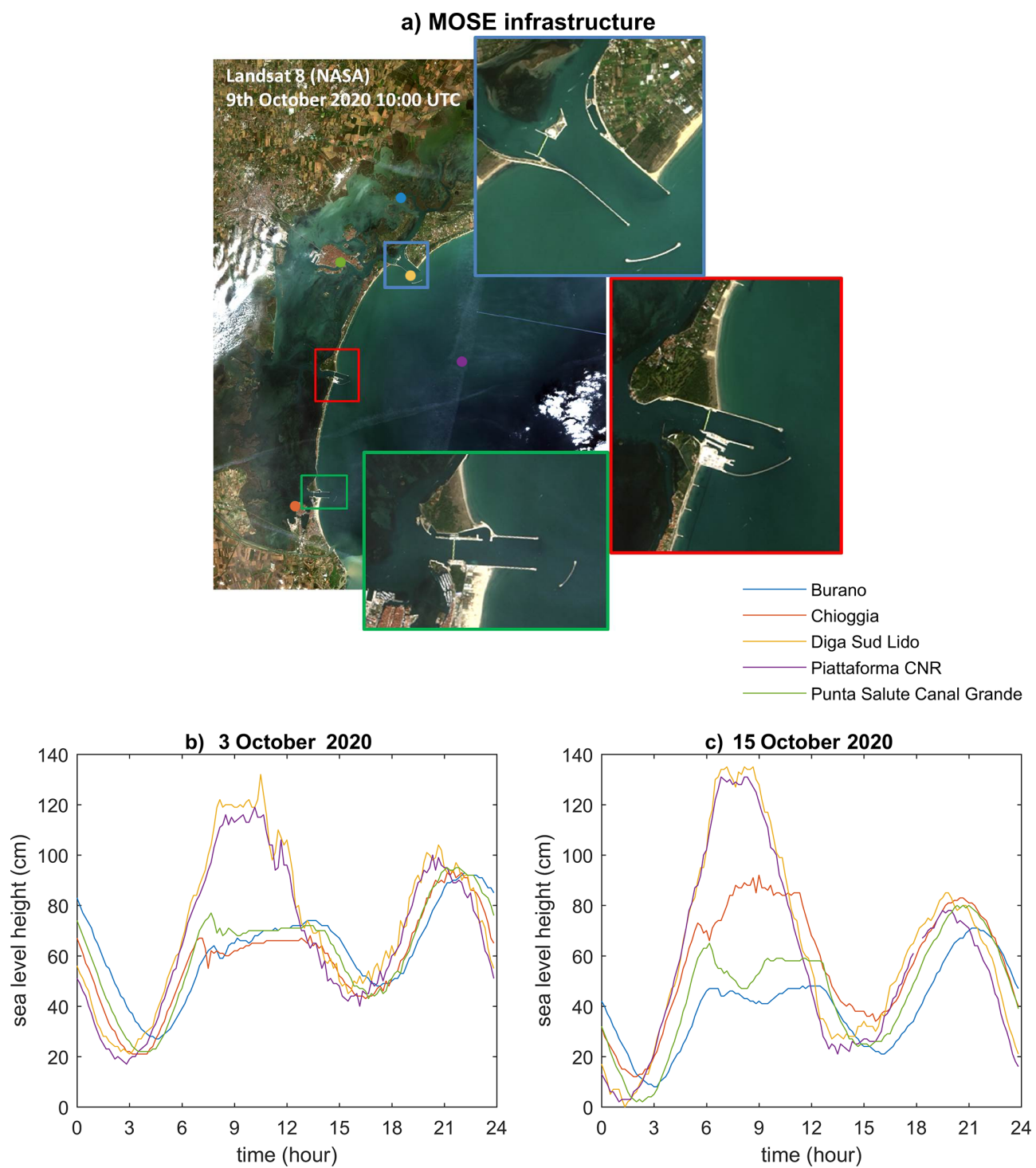

Figure 2. Pre-operational closures of the MoSE in October 2020. (a) Pseudo true colour pan-sharpened Landsat 8 Operational Land Imager (OLI) imagery, acquired on 9 October 2020, showing the Venetian Lagoon inlets during a test closure of the MoSE. The Landsat 8 image is available from the U.S. Geological Survey and was processed by CNR-ISMAR. (b) The water height anomalies measured on 3 October 2020 by tide gauges located within the Venetian Lagoon (Burano, Chioggia, and Punta della Salute - Canal Grande) and in the open Adriatic Sea (Diga Sud Lido and Piattaforma CNR), showing the effect of the MoSE closure on the water height level inside the lagoon. Panel (c) is the same as (b) but for the MoSE closure on 15 October 2020.

tary waves and mesoscale atmospheric systems can also provide a significant contribution. Together with these meteorological processes, the contribution of the regular tides has to be considered, which can add about $50 \mathrm{~cm}$ during a spring tide (Ferrarin et al., 2015). Another flood process is seiches, i.e. free oscillations in the Adriatic Sea triggered by the wind set-up. The main seiches, which have a period of around $23 \mathrm{~h}$, very close to that of the diurnal tides, overlie the meteorological and tidal processes and may cause flooding - even if the main meteorological conditions have calmed down (Bajo et al., 2019). These processes and their superposition leading to compound events are described in L2021.

The positive water level anomaly in the Adriatic Sea enters the lagoon nearly undisturbed through the deep inlets (8$13 \mathrm{~m})$ and then reaches and floods the city centre of Venice (Umgiesser et al., 2004; U2021). While there might be some local water height differences due to the wave set-up outside the inlets and wind stress inside the lagoon, the water height in the city of Venice closely follows the level outside the lagoon. Wave run-up and infra-gravity waves are not relevant for the water height in the city centre, although they may have 


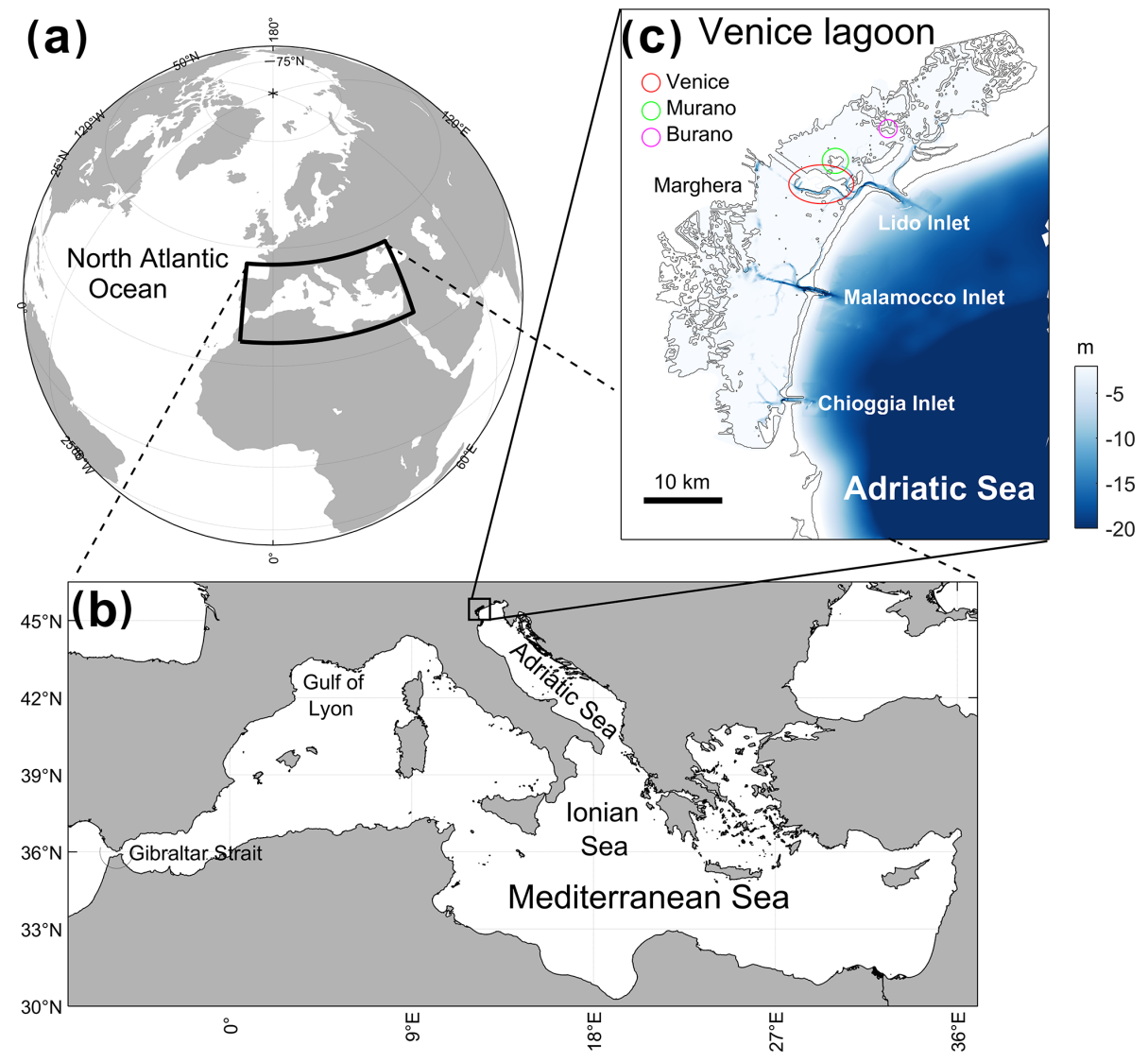

Figure 3. The lagoon of Venice in the global context. (a) The Mediterranean Sea is connected with the North Atlantic Ocean through the Strait of Gibraltar. (b) The Venetian Lagoon is located along the northern coast of the Adriatic Sea, a subbasin of the eastern Mediterranean Sea. (c) The historic centre of Venice (indicated) is located in the middle of the Venetian Lagoon.

an effect at the sea side of the barrier islands separating the lagoon from the sea (see L2021).

\section{Key insights from the papers}

The important potential role of compound events (resulting from the superposition of the different contributions introduced in Sect. 3) for causing extreme sea levels emerges clearly from L2021. Many past studies concentrated on the storm surge contribution, which was the determinant contribution for the 4 November 1966 and the 19 October 2018 events, and on the need for a precise prediction of its timing in relation to the phase of the astronomical tide and preexisting seiches. However, the presence of other factors can determine extreme sea level events when they act constructively, namely planetary atmospheric wave surges and meteotsunamis, even if their individual magnitude is not exceptionally large (L2021), as was apparent during the recent 12 November 2019 event (Ferrarin et al., 2021). This poses a great challenge to the prediction of extreme sea levels (U2021) and the management of MoSE. Furthermore, historic floods show large interdecadal and interannual fluc- tuations, whose dynamics are not sufficiently understood (L2021), preventing reliable seasonal predictions.

The water height forecast (U2021) has paramount importance because it is needed by civil protection for flood warnings and by the consortium that operates the mobile barriers (MoSE), which are currently in a pre-operational phase at the inlets. Considering the operativity of MoSE, a reliable forecast should be able to satisfy the requirements of the different stakeholders, especially in terms of the forecast range and error statistics (Umgiesser, 2000). The present plan is to operate the barriers and to close the lagoon on the basis of the forecast water level, wind and rain only a few hours before the event. The port authority is particularly sensitive to unnecessary closures, which produce unmotivated economic losses by limiting the port operations, and want to anticipate (in the range from 1 to $2 \mathrm{~d}$ ) the decision to close in order to the facilitate proper management of the ingoing and outgoing ship traffic. Residents, shopkeepers, and most commercial activities in Venice would support a more conservative approach that minimises the risk of flood damages to goods and property. Therefore, the port authority is interested in avoiding false alarms, while other stakeholders are worried 
about missing closures. Tourist activities would, in general, be concerned by cancellations of reservations and visits that may be caused by an excessive water level forecast.

An operational forecasting system has been in place for the last 40 years, but further developments are needed to match the requests of stakeholders and the requirements for operating MoSE. A lack of accuracy in the forecast of the compound event that led to the exceptional water height maximum on 12 November 2019 produced a severe underestimate (up to $45 \mathrm{~cm}$ ) of the maximum event height by all available forecast systems (Ferrarin et al., 2021). The need to improve the operational forecasting system has been further demonstrated by the flooding of the city on 8 December 2020, when the MoSE was not operated despite being available because the forecast underestimated the height of the water level. Therefore, further developments are needed, particularly the use of ensemble methods, assimilation of real-time data, and the exploitation of multimodel approaches (U2021). Implementing these features in the forecasting systems can (and should) be done to guarantee an improved and adequate water level forecast in the near future.

RSL rise is the factor that has produced the past increase in the Venice flood frequency. Z2021 show that the $2.5 \mathrm{~mm}$ per year RSL trend in Venice has been caused in approximately equal parts by land subsidence and mean sea level (MSL) rise. L2021 show that the increased frequency of floods is attributed to such a RSL rise, with no robust evidence of the intensification of the meteorological conditions associated with extreme water heights. Figure 4 summarises these results by showing the RSL rise in Venice and the corresponding increase in the frequency of water height maxima above $120 \mathrm{~cm}$, which has increased from less than two events per decade (average frequency during the first half of the 20th century) to 40 events in the last decade (2010-2019). Considering a lower $(110 \mathrm{~cm})$ water height threshold, the number of events has increased from 4.2 events per decade to 95 events per decade (L2021).

Uncertainty in future greenhouse gas emissions (largely depending on governmental and societal decisions) and structural modelling uncertainties (particularly in relation to the melting of the large Greenland and Antarctic ice sheets) lead to a wide range of possible future sea level rise scenarios (Z2021). Figure 4 shows that the past MSL in Venice closely follows the MSL evolution of the subpolar North Atlantic. The differences between these two time series consist of the interannual and interdecadal sea level fluctuations in the North Adriatic, with no sustained different trends. This study and other studies indicate that future subregional deviations play a minor role in long-term planning and add an uncertainty estimated to be of the order of $\pm 10 \mathrm{~cm}$ to the RSL at the end of the 20th century (Z2021). Figure 5 shows a RSL rise range from about 30 to $110 \mathrm{~cm}$ at the end of the $21 \mathrm{st}$ century (with a wider 10 to $120 \mathrm{~cm}$ range, accounting for the uncertainty associated with subregional deviations). This could grow to above $180 \mathrm{~cm}$ if an unlikely, but plausible, high-end

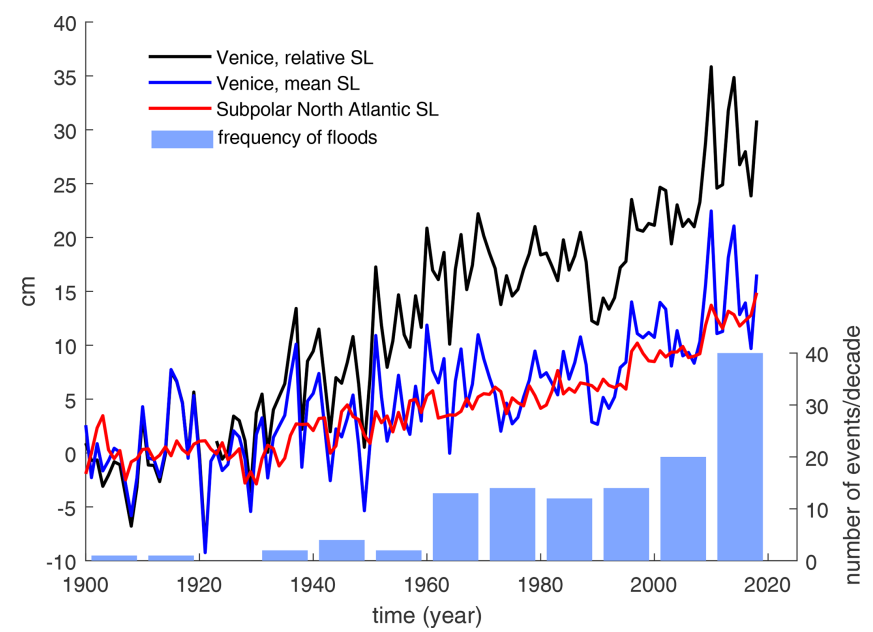

Figure 4. Comparison between the historical evolution of average sea level and flooding events in Venice and the link with larger-scale changes in sea level. The Venetian sea level is reported as the annual average relative sea level and is obtained from measurements by the Punta della Salute tide gauge (black line) and as the annual average mean sea level obtained by removing the local subsidence estimate from the tide gauge data (blue line; Z2021). The red line illustrates the evolution of the basin-averaged sea level for the subpolar North Atlantic, as estimated by Frederikse et al. (2020). Blue bars show the number of floods exceeding the threshold of $120 \mathrm{~cm}$ within each decade.

scenario is realised. These values are obtained by considering the regional analysis of future RSL (Thiéblemont et al., 2019), integrated by accounting for centennial natural vertical land movement occurring at the past rate, and adding a further $10 \mathrm{~cm}$ of uncertainty caused by subregional deviations from the subpolar North Atlantic sea level (Z2021).

Future RSL rise will be the key factor determining the future duration of extreme water heights above the safeguard thresholds, which correspond to the duration of the closures of the inlets by the MoSE mobile barriers. Figure 5 reports the RSL thresholds for the closures, based on the consensus between Lionello (2012) and Umgiesser (2020), and it shows that the period of closure will grow at a rate controlled by the RSL rise. Closing the inlets for 3 weeks per year is unlikely before the 2040s but virtually certain before the end of this century, even under a low-emission scenario (RCP2.6). Closures of 2 months per year are unlikely before the late 2050s, even under a high-end emission scenario (RCP8.5). However, they become virtually certain by the late 2080s under a high-emission scenario and about as likely as not before the end of this century for a low-emission scenario. Note that a 6-month closure per year (which can be used as the criterion for considering the present defence strategy to be inadequate and requiring new, additional actions) is likely to occur before the end of this century under a high-emission scenario. 


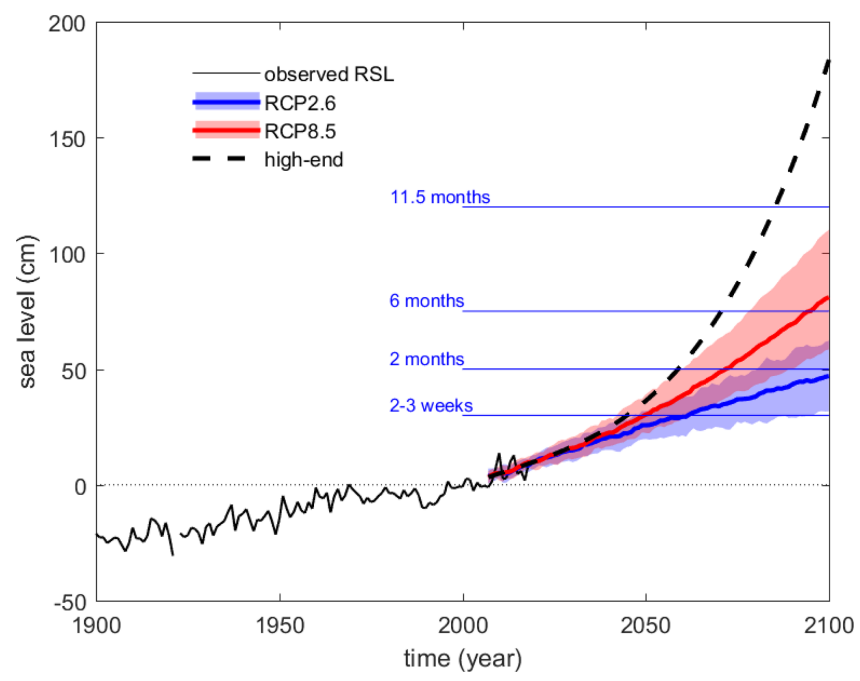

Figure 5. Projected relative sea level change in Venice in the context of historical observations. Observations are the annual mean tide gauge relative sea level height anomalies with respect to the 2000-2007 average. Projections are based on two reference scenarios of anthropogenic greenhouse gas emissions, namely Representative Concentration Pathway 2.6 (RCP2.6; low emission scenario) and RCIP8.5 (strong emission scenario), and a high-end scenario illustrating a plausible evolution obtained by combining the highest estimates of all individual contributions to relative sea level rise (shading - 5-95 percentile range; line - median). The horizontal blue lines show the relative mean sea level thresholds for annual persistence of the relative sea level above the present safeguard level (persistence durations of 2-3 weeks; 2, 6, and 11.5 months have been considered). These time intervals approximately correspond to the annual duration of the expected closures of MoSE.

RSL rise will also be the key factor responsible for the future increase in extreme sea level frequency and height, while the reduction in the intensity of meteorological events and the changes in tidal regimes will play a secondary role (L2021). In the case of a high-emission scenario the magnitude of one sea level event in 100 years at the northern Adriatic coast is projected to increase by up to $65 \%$ in 2050 and $160 \%$ in 2100 with respect to the present value, thereafter continuing to increase through the 22nd century and beyond (L2021).

\section{Implications for future flooding and its management}

The insights from the three review articles have important implications for our understanding of the future occurrence of floods in Venice and their management. They demonstrate that RSL rise has been and will continue to be the main driver of increasing extreme water heights and increasing flood potential. Projected future RSL rise is the product of local changes due to subsidence and regional and global trends linked to human-induced climate change. Natural background subsidence (up to around $1 \mathrm{~mm}$ per year) due to enduring long-term geological trends apparent over many centuries and longer is inevitable in Venice (Z2021). Importantly, however, most subsidence in the last 100 years was due to human actions (largely groundwater withdrawal). Since the 1970s, regulation and the provision of alternative sources of water for industrial, agricultural, and civil use have avoided such subsidence. It is important that these successful regulations to control human-induced subsidence continue to be enforced in the future. Efforts could even be strengthened further, as some localised subsidence can still be measured linked to construction works and related activities (Tosi et al., 2018). Costs, benefits, and the practicality of the required measures might be considered in the context of building regulations and permits. Therefore, future humaninduced contributions to local subsidence can be controlled based on historic experience and awareness.

In contrast, most ongoing and projected future climateinduced sea level rise is a result of global actions concerning greenhouse gas emissions and the resulting temperature rise. It is, therefore, of paramount importance to identify and support collective global actions to reduce such emissions, especially with respect to the Paris Agreement. It is also important for Venice, as in other coastal jurisdictions around the world, to stay aware of future expectations about sea level rise and to plan accordingly. The regular assessments of the Intergovernmental Panel on Climate Change (IPCC) are especially important in this regard, with the Sixth Assessment to be published in 2021. Currently, it is not clear whether the world is heading towards emissions more comparable to RCP4.5 or RCP6.0 (Hausfather and Peters, 2020) rather than to RCP8.5 (Schwalm et al., 2020). With further reductions, having emissions close to RCP2.6 (following the Paris Agreement) is a plausible, albeit challenging, target to achieve. However, the recent IPCC Special Report on the Ocean and Cryosphere in a Changing Climate (Oppenheimer et al., 2019) has emphasised the fundamental point that stabilising temperature does not stabilise sea level but, rather, the rate of sea level rise.

Hence, some RSL rise is inevitable for Venice, and extreme water heights and flood potential will grow; uncertainty concerns only the rate of this increase. Significant aspects of this uncertainty relate to future emissions, the response of the Greenland and Antarctic ice sheets to global temperature rise, and future subsidence of the Venetian Lagoon. It is important to remember that Venice has adapted to RSL rise through its more than 1000-year history. Hence, the adaptation actions since the 1966 floods, comprising both local adaptation (by raising parts of the historical centre) and large-scale adaptation for the whole lagoon (the construction of the MoSE barriers) continue this tradition. With the MoSE barriers being fully commissioned in 2021, the risks of flooding in Venice will be greatly reduced. However, as the RSL is still rising and is projected to rise beyond the 21 st century, even with the Paris Agreement being fully implemented, ultimately even this new, world-class adaptation system will be challenged. The critical question is when a new adaptation 
strategy will be required, while being aware that, considering the uncertainty of future RSL scenarios, it might happen, in the worst case, within a few decades or maybe much later, during the 22nd century. This suggests that experience from the long-term planning for sea level rise under uncertainty that is being carried out in locations such as London (Ranger et al., 2013) and is drawing on adaptation pathways more widely (Haasnoot et al., 2019) should also be considered in the Venetian context.

Finally, the recognition of the possible role of compound flood events due to superimposed extreme water heights drivers shows the potential for improved flood forecasts in Venice, which, in turn, will allow for better control of the MoSE barriers. Thus, the improved understanding and forecasting of short-term events will contribute to better longterm adaptation in Venice. With such improved forecasts and greater confidence in those forecasts, this has the potential to extend the operational range of the MoSE barriers and its life as an adaptation tool for Venice. This needs to be more fully explored.

Data availability. The subpolar North Atlantic sea level data, as estimated by Frederikse et al. (2020a) and used in Fig. 4, are available at https://doi.org/10.5281/zenodo.3862995 (Frederikse et al., 2020b). The data on the frequency of floods (shown in Fig. 4) are available at https://www.comune.venezia.it/it/content/ distribuzione-decennale-delle-alte-maree-110-cm (CPSM, 2021). Observed tide gauge data (Punta della Salute) are available from the ISPRA website at https://www.venezia.isprambiente.it/index. php?folder_id=20\&stazione_id=129\&tipo_dati_id=1\&view=year (ISPRA, 2021). Historical tide gauge data for Venice (used in Fig. 4) and sea-level projections for Venice for RCP2.6, RCP8.5, and a high-end scenario (used in Fig. 5) are available at https://doi.org/10.5281/zenodo.5139890 (Zanchettin, 2021b).

Author contributions. PL coordinated the writing of the article. PL, GU and DZ contributed the material from the articles L2021, U2021, and Z2021, respectively. RJN led the discussion in Sect. 5. DZ produced Figs. 3, 4, and 5.

Competing interests. The authors declare that they have no conflict of interest.

Disclaimer. Publisher's note: Copernicus Publications remains neutral with regard to jurisdictional claims in published maps and institutional affiliations.

Special issue statement. This article is part of the special issue "Venice flooding: understanding, prediction capabilities, and future projections". It is not associated with a conference.
Acknowledgements. The authors thank Federica Braga of ISMARCNR for providing the image used in Fig. 2a. The scientific activity by Georg Umgiesser and Davide Zanchettin, performed in the Research Programme Venezia 2021, with the contribution of the Superintendency for the Public Works of Veneto, Trentino Alto Adige, and Friuli Venezia Giulia, provided through the concessionary of the state of Consorzio Venezia Nuova and coordinated by Consorzio per il Coordinamento delle Richerche inerrenti al Sistema Lagunare di Venezia (CORILA), is acknowledged.

The authors thank Gianfranco Tagliapietra for the historical photo of the flooding of St Mark's Square on 4 November 1966.

Review statement. This paper was edited by Uwe Ulbrich and reviewed by two anonymous referees.

\section{References}

Bajo, M., Međugorac, I., Umgiesser, G., and Orlić, M.: Storm surge and seiche modelling in the Adriatic Sea and the impact of data assimilation, Q. J. Roy. Meteor. Soc., 145, 2070-2084, 2019.

Bondesan, A. and Furlanetto, P.: Artificial fluvial diversions in the mainland of the Lagoon of Venice during the 16th and 17th centuries inferred by historical cartography analysis, Géomorph. Rel. Proc. Environ., 18, 175-200, 2012.

Cavaleri, L., Bertotti, L., Buizza, R., Buzzi, A., Masato, V., Umgiesser, G., and Zampieri, M.: Predictability of extreme meteo-oceanographic events in the Adriatic Sea, Q. J. Roy. Meteor. Soc., 136, 400-413, 2010.

Cavaleri, L., Bajo, M., Barbariol, F., Bastianini, M., Benetazzo, A., Bertotti, L., Chiggiato, J., Ferrarin, C., Trincardi, F., and Umgiesser, G.: The 2019 Flooding of Venice and its implications for future predictions, Oceanography, 33, 42-49, 2020.

CPSM: Distribuzione decennale delle alte maree, available at: https://www.comune.venezia.it/it/content/ distribuzione-decennale-delle-alte-maree-110-cm, last access: 1 August 2021.

De Zolt, S., Lionello, P., Nuhu, A., and Tomasin, A.: The disastrous storm of 4 November 1966 on Italy, Nat. Hazards Earth Syst. Sci., 6, 861-879, https://doi.org/10.5194/nhess-6861-2006, 2006.

Enzi, S. and Camuffo, D.: Documentary sources of the sea surges in Venice from ad 787 to 1867, Nat. Hazards, 12, 225-287, 1995.

Ferrarin, C., Tomasin, A., Bajo, M., Petrizzo, A., and Umgiesser, G.: Tidal changes in a heavily modified coastal wetland, Cont. Shelf Res., 101, 22-33, 2015.

Ferrarin, C., Bajo, M., Benetazzo, A., Cavaleri, L., Chiggiato, J., Davison, S., Davolio, S., Lionello, P. Orlić, M., and Umgiesser, G.: Local and large-scale controls of the exceptional Venice floods of November 2019, Prog. Oceanogr., 197, 102628, https://doi.org/10.1016/j.pocean.2021.102628, 2021.

Frederikse, T., Landerer, F., Caron, L., Adhikari, S., Parkes, D., Humphrey, V. W., Dangendorf, S., Hogarth, P., Zanna, L., Cheng, L., and $\mathrm{Wu}$, Y.-H.: The causes of sea-level rise since 1900, Nature, 584, 393-397, 2020a.

Frederikse, T., Landerer, F., Caron, L., Adhikari, S., Parkes, D., Humphrey, V. W., Dangendorf, S., Hogarth, P., Zanna, L., Cheng, L., and Wu, Y.-H.: Data supplement for "The 
causes of sea-level rise since 1900", Zenodo [data set], https://doi.org/10.5281/zenodo.3862995, 2020b.

Gregory, J. M., Griffies, S. M., Hughes, C. W., Lowe, J. A., Church, J. A., Fukimori, I., Gomez, N., Kopp, R.E., Landerer, F., Le Cozannet, G., Ponte, R.M., Stammer, D., Tamisiea, M. E., and van de Wal, R. S.: Concepts and terminology for sea level: Mean, variability and change, both local and global. Surv. Geophys., 40, 1251-1289, 2019.

Haasnoot, M. Brown, S., Scussolini, P., Jimenez, J. A., Vafeidis, A. T., and Nicholls, R. J.: Generic adaptation pathways for coastal archetypes under uncertain sea-level rise, Environm. Res. Comm., 1, 071006, https://doi.org/10.1088/2515-7620/ab1871, 2019.

Hausfather, Z. and Peters, G. P.: Emissions - the "business as usual" story is misleading, Nature 577, 618-620, 2020.

Istituto Superiore per la Protezione e la Ricerca Ambientale (ISPRA): Punta della Salute tide gauge data, available at: https://www.venezia.isprambiente.it/index.php?folder_ id=20\&stazione_id=129\&tipo_dati_id=1\&view=year, last access: 1 August 2021.

Lionello, P.: The climate of the Venetian and North Adriatic region: Variability, trends and future change, Phys. Chem. Earth., 40-41, $1-8,2012$

Lionello, P., Cavaleri, L., Nissen, K. M., Pino, C., Raicich, F., and Ulbrich, U.: Severe marine storms in the Northern Adriatic: Characteristics and trends, Phys. Chem. Earth., 40-41, 93-105, 2012.

Lionello, P., Barriopedro, D., Ferrarin, C., Nicholls, R. J., Orlić, M., Raicich, F., Reale, M., Umgiesser, G., Vousdoukas, M., and Zanchettin, D.: Extreme floods of Venice: characteristics, dynamics, past and future evolution (review article), Nat. Hazards Earth Syst. Sci., 21, 2705-2731, https://doi.org/10.5194/nhess21-2705-2021, 2021

Oppenheimer, M., Glavovic, B., Hinkel, J., Van de Wal, R., Magnan, A. K., Abd-Elgawad, A., Cai, R., Cifuentes-Jara, M., Deconto, R. M., and Ghosh, T.: Sea level rise and implications for low-lying islands, coasts and communities, IPCC Special Report on the Ocean and Cryosphere in a Changing Climate, edited by: Pörtner, H.-O., Roberts, D. C., Masson-Delmotte, V., Zhai, P., Tignor, M., Poloczanska, E., Mintenbeck, K., Alegría, A., Nicolai, M., Okem, A., Petzold, J., Rama, B., and Weyer, N. M., available at: https://www.ipcc.ch/site/assets/uploads/sites/ 3/2019/11/08_SROCC_Ch04_FINAL.pdf (last access: 1 August 2021), 2019.

Polli, S.: Propagazione della marea nella laguna di Venezia, Ann. Geophys., 5, 273-292, 1952.

Ranger, N., Reeder, T., and Lowe, J.: Addressing “deep” uncertainty over long-term climate in major infrastructure projects: four innovations of the Thames Estuary 2100 Project, EURO J. Decis. Process., 1, 233-262, 2013.
Schwalm, C. R., Glendon, S., and Duffy, P. B.: Reply to Hausfather and Peters: RCP8. 5 is neither problematic nor misleading, P. Natl. Acad. Sci. USA, 117, 27793-27794, 2020.

Thiéblemont, R., Le Cozannet, G., Toimil, A., Meyssignac, B., and Losada, I. J.: Likely and High-End Impacts of Regional SeaLevel Rise on the Shoreline Change of European Sandy Coasts Under a High Greenhouse Gas Emissions Scenario, Water, 11, 2607, https://doi.org/10.3390/w11122607, 2019.

Tosi, L., Lio, C. D., Teatini, P., and Strozzi, T.: Land subsidence in coastal environments: knowledge advance in the Venice Coastland by TerraSAR-X PSI, Remote Sens., 10, 1191, https://doi.org/10.3390/rs10081191, 2018.

Umgiesser, G., Melaku Canu, D., Cucco, A., and Solidoro, C.: A finite element model for the Venice Lagoon. Development, set up, calibration and validation, J. Marine Sys., 51, 123-145, 2004.

Umgiesser, G.: The impact of operating the mobile barriers in Venice (MOSE) under climate change, J. Nat. Conserv., 54, 125783, https://doi.org/10.1016/j.jnc.2019.125783, 2020.

Umgiesser, G., Bajo, M., Ferrarin, C., Cucco, A., Lionello, P., Zanchettin, D., Papa, A., Tosoni, A., Ferla, M., Coraci, E., Morucci, S., Crosato, F., Bonometto, A., Valentini, A., Orlić, M., Haigh, I. D., Nielsen, J. W., Bertin, X., Fortunato, A. B., Pérez Gómez, B., Alvarez Fanjul, E., Paradis, D., Jourdan, D., Pasquet, A., Mourre, B., Tintoré, J., and Nicholls, R. J.: The prediction of floods in Venice: methods, models and uncertainty (review article), Nat. Hazards Earth Syst. Sci., 21, 2679-2704, https://doi.org/10.5194/nhess-21-2679-2021, 2021.

Zanchettin, D., Traverso, P., and Tomasino, M.: Observations on future sea level changes in the Venice lagoon, in: Lagoons and Coastal Wetlands in the Global Change Context: Impacts and Management Issues, edited by: Viaroli, P., Lasserre, P., and Campostrini, P., Hydrob., 577, 41-53, 2007.

Zanchettin, D., Bruni, S., Raicich, F., Lionello, P., Adloff, F., Androsov, A., Antonioli, F., Artale, V., Carminati, E., Ferrarin, C. Fofonova, V., Nicholls, R. J., Rubinetti, S., Rubino, A., Sannino, G., Spada, G., Thiéblemont, R., Tsimplis, M., Umgiesser, G., Vignudelli, S., Wöppelmann, G., and Zerbini, S.: Sea-level rise in Venice: historic and future trends (review article), Nat. Hazards Earth Syst. Sci., 21, 2643-2678, https://doi.org/10.5194/nhess21-2643-2021, 2021a.

Zanchettin, D., Bruni, S., Thieblemont, R., and Rubinetti, S.: Data from the article Zanchettin, D. et al.: Sea-level rise in Venice: historic and future trends (review article), Zenodo [data set] https://doi.org/10.5281/zenodo.5139890, 2021b. 